crushing action. When this postorior line of attachment has been reacbed the pressure of the thumb of the hand holding the guillotine should not be enough to force it home, owing to the bluntness of the guillotine; it is at this juncture that the other thumb should cease to press on the anterior pillar of the fauces, and the hand thus freed be used to force home the guillotine. The tonsil will always come away with the guillotine, owing to this crushing of the tissues. Since it is necessary to get a good view, it is advisable to pass immediately from the one tonsil to the other before blood obscures the view. Failure tor see means that: the furnow between the tonsil and the posterior: pjlar of the farces may not be hit off, and that the anterior pillar of the fauces may be damaged. I often take away a thin edge of mucous membrane on the anterior pillar of the fauces. It is easily done without touching the musculature. After the enucleation of tonsils a definite smooth-walled cavity corresponding to the buried portion of the tonsil is felt with the finger. On examination of the tonsil the : surface of the buried portion will similarly be seen to be smooth with the thin grey capsule of the tonsil covering it. The completeness of this capsule is the demonstration of complete enúcleation.

Sometimes, especially in adults, the tonsils have to be removed when there is mo faucial prominence at all; there may be an excavation. In cases such as this the operation presents no increased difficulties, since the posterior pillar of the fauces is a guiding mark to the posterior border of the tonsil. Visibility is all-important to maintain the position of a guilkotine whilst the tonsil is pressed into the guillotine. I have removed a tonsil which on examina. tion afterwards was eup-shaped, consisting of an excavated buried portion of tonsil only.

The removal of adenoids calls for no other remarks beyond what has been isaid with regard to removing them with one sweep of the curette. It is always well to feel and: steady the cunette against the posterior border of the nasal septum where it touches the roof of the nasopharynx. This can quite well be done without any damage to what is a relatively fragile structure. One quiak sweeping movement with maintenance of pressure backward on to the pharyngeal wall is then all that is necessary. At the end of operation the child can be.turned sideways or face downwards to allow of the escape of blood; but is kept wrapped up, to avoid struggling, until such time as consciousness returns.

BEFFRBNCE.
1 On Enucleation of Tonsils with the Guillotine, by S. S. Whillis M.D., and C. F. Pybus, M.S., F.R.C.S., BRITISE MEDIOAL JoURNAL

\section{A METHOD OF ENUCLEATING TONSILS WHICH LESSENS BLEEDING.}

PETER MACDONALD, M.A., M.D.,

HONORARY SURGEON, EAR, NOSE, AND TEROAT DEPARTMENT, YORK COUNTY HOSPITAL.

THE " reverse guillotine" method of enucleating tonsils, first described in this country by Whillis, is, I suppose, that most commonly now employed, and I personally use it almost exclusively, except that I use my thumb, and not my forefinger, to press the tonsil through the guillotime ring; and after trying various guillotines I came to the conclusion that the Howarth guillotine, with sharp and blunt blades, was much the most convenient of the instrunents made for this purpose. I have come to use the blunt blade only in the vast majority of cases, keeping the sharp blade in reserve for cases where the fibrous attachments of the tonsil are so tough that they do not readily give way to the blunt blade-a condition found only in a small minority of cases operated on.

To obviate bleeding, and also to lessen the liability of the patients either swallowing blond or sucking blood into the larynx, I have recently somewhat modified my methods. It is much more corrvenient to engage the tonsil in the guillatine with the patient on the back than on the side, but to prevent blood from accumulating in the pharynx, with risk of its passing into the larynx or oesophagus, I like to have the patient on the side with the face turned somewhat down before performing anycatting $;$ so that any blood runs down out of the mouth.

I adopted, acoordingly, the following procedure: The patient is anaesthetized on the back and the operation field well illuminated with a head lamp or frental mirror. Standing on his left side facing him, I first engage the left tonsil in the ring of the guillotine, shut down the blade by the hanale lerer and give this closed bandle to an assistant (navially a nurse) to hold, and then engage the right tonsil with the second guillotine and close the blade and hold the haidile myself.

On this being completed, the patient is tarned on to the left side awd the face turned somewhat down. Up to this time there is practioally no blood in the month, and as the mouth is now turned down, any blood from the subsequent operative procedure will run out of the mouth over the edge of the operating table. This manourre almost com pletely obviates the stwallowing of blood during the rest of the operation.

I now remove the; bonsils, and I do so not by cutting ant or tearing out; but, asing the closed instrument in the same way as a pressure forceps is employed to perform torsion on a small artery, I twist the tonsil until the podicle of fibrous tissue, engaged between the guillotine blade and the ring, containing the principal blood vessels of the tonsil, gives way.

In this way the bleeding from the tonsils is reduced torr minimum. The tonsil is removed in its oapsule, and with rare exceptions the removal is complete. If necessary, adenoids are now removed with the face still turned somewhat down, so that blood from these also runs out of the mouth. On completion of the operation the patient is turned completely over on to the chest and face, with the head hanging down over the edge of the table, and on removal to bed or re covery couch, oare is taken that the patient is not allowed to lie on the back until there is a con siderable degree of re covery from the anaes. thetic.

The inconvenience of handing the closed handle of the : guillotine to $a n$ assistant to loold and the risk of slipping involved, soon made it evident that it was desirable to employ, for the first guillotine at least, one with a locking attachment to lock the blade, such as the ratchet of the Elphick " haemostatic guillotine"

The Elphick guillotine, however, has the handle attached to the blade at right angles; and as the obtase angle position of the handle in the Howarth guillotine has a great advantage, and also as the sernated edge of the crushing blade of the Elphick has no advantage which II can see, I got Messrs. Down to make me a guillotine which is really a modification of Howarth's.

The prinoipal modification is the ratchet attachment to lock the blade in the olosed position, but I had the gaillotine made also with interchangeable ring and blades for different sizes of tonsils, and with the blunt blade very blunt. A small modification, but an important one, is that the end of the lever pushing the blade home is tarned over to hold the sliding blade down to its bed, as I faund in some of my Howarth's guillotines that firm pressure on the handle sometimas forced the aliding blade to ride ap 
over the end of the lever-a rather awkward contretemps in the middle of an operation.

The instrument can also be used as a haemostatic guillotine, and left in situ for five minutes, as adrocated by $\mathrm{La}$ Force.

I find by the method above described that while in the vast majority of the cases removal of the tonsil is com plete, there is no greater amount of sloughing of the bed of the tonsil t'an when a sharp blade with cutting edge is used. The loss of blood is markedly lessened, as also the risk of serious haemorrhage. The amount of blood swallowed is reduced to a minimum.

The sister in charge of my recovery wards is quite clear that post-operative sickness is lessened, and in consequence, where patients have to go home the same day, as in hospital practice is often unfortunately necessary, they are sooner fit for removal.

\section{RELATION BETWEEN THE GENERAL NERVOUS SYSTEM AND SYMPTOMS OF “D.A.H.” IN NEURAS'THENIC PA'IIEN'T'S.}

\author{
H. W. DAVIES, M.B., B.S., Captain A.A.M.C., \\ AND \\ J. G. PRIESTLEY, M.C., B.M.Oxon.
}

(From the Clinical Laboratory, Ashhurst War Hospital, Littlemore.)

AN investigation ${ }^{1}$ carried out by one of us in conjunction with J. S. Haldane and J. C. Meakins at No. 15 Canadian General Hospital, Taplow, during 1918, on patients suffering from symptoms of D.A.H. - chiefly in consequence of irritant gas poisoning-led to the recognition of the im. portance of the symptom of shallow breathing. This symptom appeared to be due to some abnormal upset of the Hering-Breuer reflex.

Hering and Breuer ${ }^{2}$ described in 1868 the reflex control of the respiratory movements. Their experiments proved that inspiration and expiration are initiated in response to afferent impulses passing up the vagus, and that a state of deflation or inflation of the lungs provides the stimulus which originates the impulse leading to inspiration and expiration respectively. Hering and Breuer's wolk, however, did not throw any light on the question as to how the depth of breathing is norm lly regulated. The nature of this regulation was made clear by the work of Haldane and Mavrogordato, ${ }^{3}$ who showed that the degree of inflation or deflation of the lungs which is necessary to excite the Hering-Breuer reflex depends upon the $\mathrm{CO}_{2}$ tension of the arterial blood.

Besides the abnormality of the Hering-Breuer reflex the patients also manifested many other functional and nervous symptoms, and consequently it seemed advisable to make some attempt to work out the relationship, if any, between their abnormal respiration and disturbance of other functions of the nervous system.

With this object in view the work was transferred to the Ashluurst War Hospital, and the present paper embodies the results of observations made there on neurastluenic patients. These patients were not selected, but were taken at random. All were admitted for "neurasthenia." The total number of patients on whom observations were made was 100 .

The first point to which attention was directed was the prevalence and severity of D.A.H. symptoms among patients admitted for neurasthenia, and with this end in view the patients were all subjected to the following examination as far as possible:

1. Pulse rate at rest.

2. Pulse rate after two minutes' work on a bicycle ergometer at 3,170 foot pounds per minute.

3. Time taken for pulse to return to resting rate.

4. Rate of respiration sitting quietly in chair.

5. Rate of respiration sitting quietly and breathing through inspiratory and expiratory valves so that the volume could be measured.

6. Volume per respiration and volume per minute.

7. Vital capacity.

8. Time during which the breath could be held $(a)$ in inspiratory, (b) in expiratory position.

In addition a note was made of any spontaneous complaint by pationts of shortness of breath on exertion.
It may be well here to point out one difficulty which we experienced-namely, that the observations were made at very rarying times after the onset of symptoms and after various kinds of treatment. Hence the patients had recovered to different degrees. In considering the results it was noticed that the patients exhibited a gradation of D.A.H. symptoms from none to moderate severity. They did not, however, except in a very few cases, show by any means such an extreme degree of severity of symptoms as was common among patients admitted directly in consequence of the effects of irritant gas.

An attempt was made to classify the cases observed under three heads: (1) Those with marked D.A.H. sym. ptoms, (2) those with definite D.A.H. symptoms, ahd (3) those with no appreciable D.A.H.

Table I gives a selection of representative results of this classification.

TABLE I.

\begin{tabular}{|c|c|c|c|c|c|c|c|c|c|c|}
\hline & 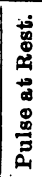 & 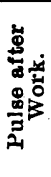 & 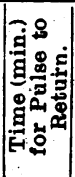 & 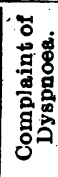 & 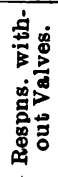 & 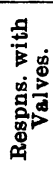 & 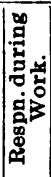 & 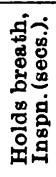 & 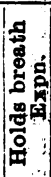 & 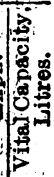 \\
\hline \multirow[t]{2}{*}{ Marked D.A.H.... } & 88 & 136 & $2+$ & No & 35 & 48 & 48 & 7 & 5 & 2.7 \\
\hline & 80 & 176 & $7+$ & Yes & 32 & 32 & 62 & 25 & 15 & 3.5 \\
\hline \multirow[t]{2}{*}{ Definite D.A.H.... } & 96 & 124 & 1 & Yes & 15 & 15 & 28 & 20 & 15 & 3.5 \\
\hline & 84 & 100 & $4+$ & No & 22 & 20 & 30 & 55 & 25 & 3.0 \\
\hline \multirow{2}{*}{$\begin{array}{l}\text { No appreciable } \\
\text { D.A.H. }\end{array}$} & 58 & 72 & $\frac{1}{2}$ & Yes & 22 & 27 & 29 & 43 & 18 & 4.0 \\
\hline & 60 & 88 & 2 & No & 13 & 26 & 22 & 57 & 33 & 3.2 \\
\hline
\end{tabular}

On examining the figures for the whole series of cases it is evident that in the several degrees of D.A.H. the regulation of the pulse and respiration are both upset, but that in the milder cases the symptoms may be manifested chiefly with respect either to the pulse or respiration.

This is shown in Table II, where two cases of mild D.A.H. are compared.

TABLE II.

\begin{tabular}{|c|c|c|c|c|c|c|c|c|c|c|}
\hline No. of Case. & 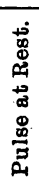 & 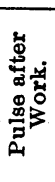 & 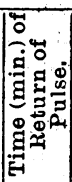 & 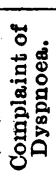 & 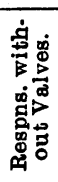 & 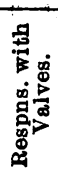 & 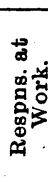 & 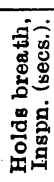 & 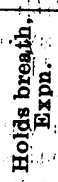 & 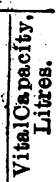 \\
\hline 97 & 72 & 116 & $3+$ & No & 18 & 18 & 22 & 42 & 25 & 2.7 \\
\hline 39 & 72 & 84 & 1 & No & 25 & 21 & 29 & 19 & 18 & 3.2 \\
\hline
\end{tabular}

Table III gives a summary of the results, and in addition shows the relation of previous infection and gas poisoning to the frequency of D.A.H. symptoms.

\begin{tabular}{ll|c|c|c}
\hline \multicolumn{7}{c}{ TABLE III. } \\
\hline
\end{tabular}

It appears from this table that of the 13 cases which showed well defined symptoms of D.A.H., 12 , or 92.3 per cent., gave a history of gas poisoning or infection, either recent or from which the symptoms dated; of the 57 cases with ill defined symptoms, 37 , or 64.9 per cent., and of the 30 cases free from D.A.H. symptoms, 14, or 46.6 per cent., gave this history.

These results accord well with the findings of Lewis and his co-workers. ${ }^{4}$ In considering them it should be borne in mind that several of the cases with no appreciable D.A.H. which are shown as having suffered from gas or infection gave a history of very slight gassing. Also in this connexion it should not be forgotten that the patients examined had been under treatment for very varying periods. Hence the figure of 46.6 per cent. hoy be talken as a maximum. 